Document downloaded from:

http://hdl.handle.net/10251/153358

This paper must be cited as:

Capelo, B.; Pérez-Sánchez, M.; Fernandes, JFP.; Ramos, HM.; López Jiménez, PA.; Costa Branco, PJ. (2017). Electrical behaviour of the pump working as turbine in off grid operation. Applied Energy. 208:302-311. https://doi.org/10.1016/j.apenergy.2017.10.039

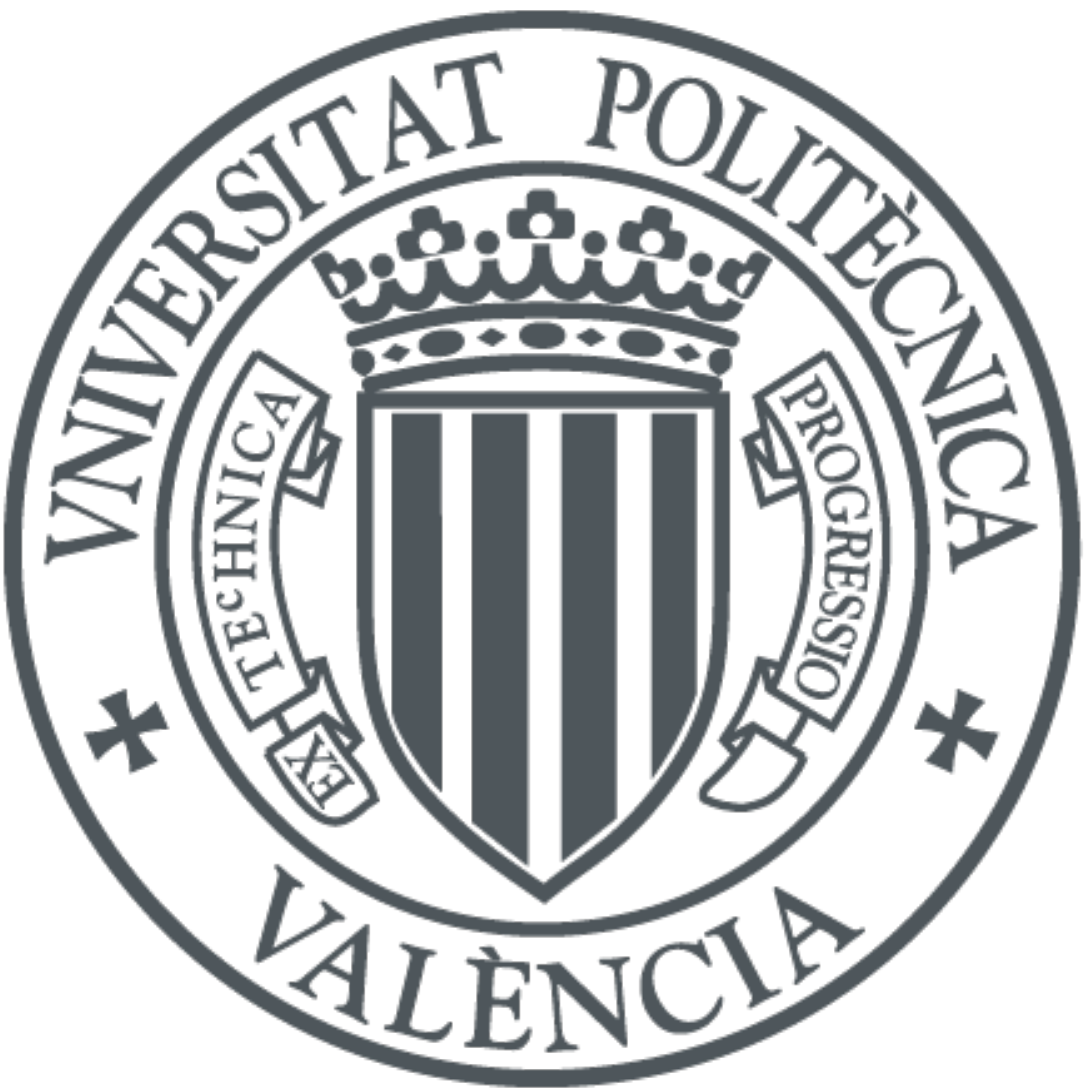

The final publication is available at

https://doi.org/10.1016/j.apenergy.2017.10.039

Copyright Elsevier

Additional Information 


\title{
Electrical behaviour of the pump working as turbine in off grid operation
}

\author{
Bernardo Capelo, Modesto Pérez-Sánchez ${ }^{1, *}$, João F.P. Fernandes² ${ }^{2}$ Helena M. Ramos ${ }^{3}$, P. Amparo \\ López-Jiménez ${ }^{1}$, P.J. Costa Branco ${ }^{2}$ \\ ${ }^{1}$ Hydraulic and Environmental Engineering Department, Universitat Politècnica de València, Valencia, 46022 \\ Spain; mopesan1@upv.es; palopez@upv.es \\ 2 Mechanical Engineering Institute (IDMEC), Instituto Superior Técnico, Universidade de Lisboa, Lisboa, 1049- \\ 001, Portugal; pbranco@tecnico.ulisboa.pt; jhpfernandes0@gmail.com \\ ${ }^{3}$ Civil Engineering, Architecture and Georesources Department, CERIS, Instituto Superior Técnico, \\ Universidade de Lisboa, Lisboa, 1049-001, Portugal; hramos.ist@gmail.com \\ * Correspondence: mopesan1@upv.es; Tel.: +0034-966-528-440
}

\begin{abstract}
The use of pumps working as turbines (PATs) connected to the electric system, in the replacement of pressure reduction valves to reduce the excessive pressure in water distribution networks, have been studied for the last years. The introduction of PATs is very important in the water-energy nexus to promote the increase of the energy savings. As consequence, the majority of the water systems does not have access to the electrical grid and, therefore, the need to study the PATs operation off-grid is necessary. In this line, the novelty of this research is the application and optimization of a PAT in water systems when the recovery solution is off-grid type. To operate correctly, the induction machine requires an external source of reactive power, which is typically provided by the electrical grid. To supply the required reactive power, a bank of capacitors is installed at the machine terminals, so-called self-excited induction generator (SEIG). The analytical model, simulation and experimental works were performed, to analyse the SEIG behaviour. The results were applied in a SEIG-PAT system obtaining the global efficiency of the system for different speeds and loads. The global efficiency decreases $47 \%$ when off-grid operation, showing the need to optimize the electrical parameters of the generator to operate as off- grid with acceptable efficiency levels. In this framework, a tuning methodology for the SEIG capacitor bank values was developed to be automatically adjusted according to the operating point of the PAT to maximize its efficiency.
\end{abstract}

KEYWORDS: Self-Excited Induction Generator (SEIG); water-energy nexus; PAT isolated to the grid; energy efficiency; 
In some contexts, such as the case of rural and remote areas, the installation of micro-hydro power sources to generate and store energy can be a good alternative to supply or complement the energy demand of these areas (Pearre and Swan, 2015; Khaled and Khalil, 2017). Possible applications of these solutions are huge, as water distribution systems are present in any infrastructure and public works all around the world. For example, in Vallada's network (Valencia, Spain), studies indicate to be possible to recover up to $188 \mathrm{MWh} /$ year for $910000 \mathrm{~m}^{3} /$ year $\left(0.201 \mathrm{kWh} / \mathrm{m}^{3}\right)$ (Pérez-Sánchez et al., 2016) that is being wasted in the WDS. If this recovery potential is extended to the worldwide irrigate consumption, that is currently $117 \mathrm{~km}^{3} /$ year in drip irrigation, the energy saved in irrigation water systems would be significant. These values can contribute to reduce the consumption of non-renewable energy that are currently used, such as the use of diesel generator (Pérez-Sánchez et al., 2017). In supply networks, the energy recovery was similar with obtained values oscillating between 1 and $5 \%$ of the provided energy in the network (Samora et al., 2016). Other examples are the pressurized water networks (irrigation and drinking) ( Samora et al., 2016; Romero et al., 2017) and wastewater treatment plants, which can improve its energy efficiency by the installation of the energy recovery in the sludge line (Longo et al., 2016; Power et al., 2017).

One viable solution is the installation of a pump working as turbine (PAT) (Ramos and Borga, 1999; Ramos and Borga, 2000; Ramos and Ramos, 2009; Pérez-Sánchez et al., 2017), which can operate under the variable operation strategy (VOS) to maximize the recovered energy used in the pumping water system (Fecarotta et al., 2016; Barbarelli et al., 2017;) and to provide balancing in the response of water distribution systems (WDS) (Ruben et al., 2016). Particularly, the impact in the overall energy efficiency of the system is great, as PATs replace valves (which lose the energy) by turbines (which recover this energy). This kind of energy recovery, complemented by energy storage units, presents a well-known technology and offers a low cost solution, easy installation and also maintenance (Oliveira e Silva and Hendrick, 2016), mainly for energy systems without a power grid connection.

One of the main concerns about the PAT are the lack of pump information given by the manufacturer for the turbine mode. Several mathematical studies have been focused on estimating the PAT curves from the available information (Dario Buono et al., 2015) for different types of turbines, as Turgo, Cross-flow and Agnew turbines (Mosè Rossi et al., 2016).

In parallel, the most typical electrical machines used in WDS systems are the induction ones, which are also capable of operating as generator. In off-grid cases, when the induction generator (IG) is not connected to the power grid, it requires a minimum capacitance to keep it excited for different loads (Eltamaly, 2002). The behaviour of a self-excited induction generator (SEIG) system off-grid type is not new. This is only valid for cases where its load impedance is relatively constant and generator motive power is characterized by small fluctuations. For example, micro-hydro run-of-the-river power plants are the ideal example mainly due to its use in rural activities (Balkair et al., 2017). On the other hand, low power and off-grid wind induction generators are characterized by large fluctuations that also demand capacitance values to be adjusted to the maximum power extraction (Ayodele et al., 2017). For PATs, recent applications as substituting pressure reducing valves (Lima et al., 2017) and even for energy recovery in WDS (Carraveta et al., 2014), the electric load and/or hydraulic power change by large flow fluctuations and therefore, the analysis acquires sense.

PAT systems with off-grid operation are characterized by different operating modes that will have an impact in the global efficiency of the energy recovery system, due to the SEIG and the hydraulic turbine efficiencies. Therefore, the electric and hydraulic regulation should be considered to maximize the recovered energy in the pressurized water system (Carravetta et al., 2013a, 2012; Carravetta et al., 2014a). A symbiosis between hydraulic and electric system is necessary in terms of excitation and regulation of the rotational speed. This application will play an important role in the future due to the high number of opportunities to install them in pressurized water systems to improve the energy recovery and reduce the energy losses. 
The aim of this work is to analyse the connection between hydraulic and electric systems to regulate it for its best overall efficiency. This is not currently analysed deeply in the expert literature since there is only analysis for the hydraulic system or connected to the grid (Pérez-Sánchez, 2017). Therefore, knowing the actual deficit in this framework, this paper presents an off-grid system of a self-excited induction generator (SEIG), in which the analytical development and computational model are used to solve the system dynamic. Once these numerical analyses were defined, an experimental application of the SEIG was developed. Finally, as novelty, the SEIG was applied on a hydraulic facility to analyse the behaviour of this hydraulic system when connected to a recovery electrical machine and to regulate it to the best system efficiency. The hydraulic analysis enabled to determine the global, hydraulic and electric efficiencies when it operates as off-grid connection. These values were then compared with the ones obtained when connected to the grid.

\section{Material and Methods}

This section describes the methodology for an automatic tuning of capacitor bank in self-excited induction generators to maximize energy efficiency in the PAT. The system will be off-grid and a standard induction motor will be used. Specifically, using an induction motor as generator significantly diminishes the cost of the PAT electrical equipment.

\subsection{Self-Excited Induction Generator. Proposed Automatic Tuning Design for PATs}

Standard squirrel-cage induction motors of small power (up to 1 or $2 \mathrm{~kW}$ ), operating as low-voltage generators, today, have their cost lower than synchronous generators, requiring not only less complex control (reduction in maintenance costs) but also showing a great robustness due to its simple form of construction. Since its inherent reversible motor/generator characteristic, when the induction machine is mechanically coupled to a prime mover, the rotor exceeds the synchronous speed and becomes generator of active power, standing out why it does not require any synchronization equipment and also having a good over-speed capability and short-circuit protection.

Fig. 1 shows a scheme of the PAT and a self-excited induction generator system. The system is composed by a variable capacitor bank connected at the induction machine terminals to supply its required reactive power. When the machine starts rotating, driven by the hydraulic turbine, a small voltage is induced in the stator coils with a frequency proportional to the rotor angular speed $\left(\omega_{r}\right)$, due to the angular variation of the machines' magnetic reluctance. With this small voltage, the capacitor bank starts producing reactive currents, thus providing reactive power $\left(Q_{S}\right)$, increasing the voltage and magnetizing the induction machine.

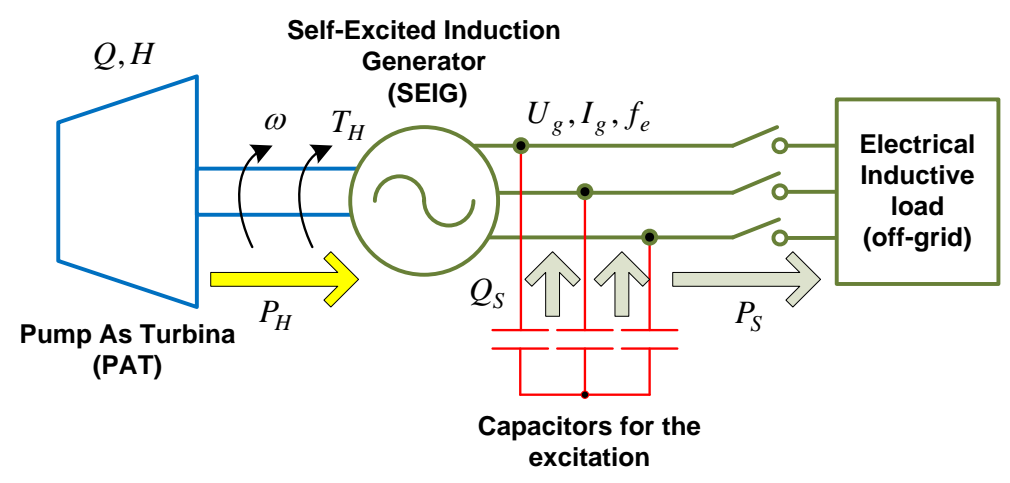

Fig. 1 - Illustrative scheme of the self-excited induction generator system for a stand-alone PAT system.

Table 1 lists the rated values of the induction generator. The hydraulic turbine, considered in this work was an Etanorm 32- $125 \mathrm{KSB}$ (Fig. 2a), with a rated speed equal to $1020 \mathrm{rpm}$ and a rated flow of $4.2 \mathrm{l} / \mathrm{s}$, as Fig. 2b shows in the turbine characteristic. However, one must notice that according the KSB turbine efficiency graph in Fig. 2c, the maximum efficiency for $1200 \mathrm{rpm}$ takes about 62\%, but for a less rate flow of $3.36 \mathrm{l} / \mathrm{s}$. Fig. 2 shows the head and efficiency curves when the machine operates in turbine mode connected to the grid. These curves were supported by the manufacturer tests. In this research, the analysis focuses on the off-grid mode and therefore, the head curve is similar to Fig. 2b, but the efficiency curve change as consequence of the installed SEIG. 
Table 1 - Nameplate information of the 3 phase squirrel-cage induction machine

\begin{tabular}{ll}
\hline \hline Rated frequency & $50 \mathrm{~Hz}$ \\
\hline Rated power & $550 \mathrm{~W}$ \\
\hline Rated current & $1.6 / 2.8 \mathrm{~A}$ \\
\hline Rated phase voltage & $230 / 400 \mathrm{~V}(\mathrm{Y} / \Delta)$ \\
\hline Power factor & 0.74 \\
\hline Rated speed & $910 \mathrm{rpm}$ \\
\hline \hline
\end{tabular}
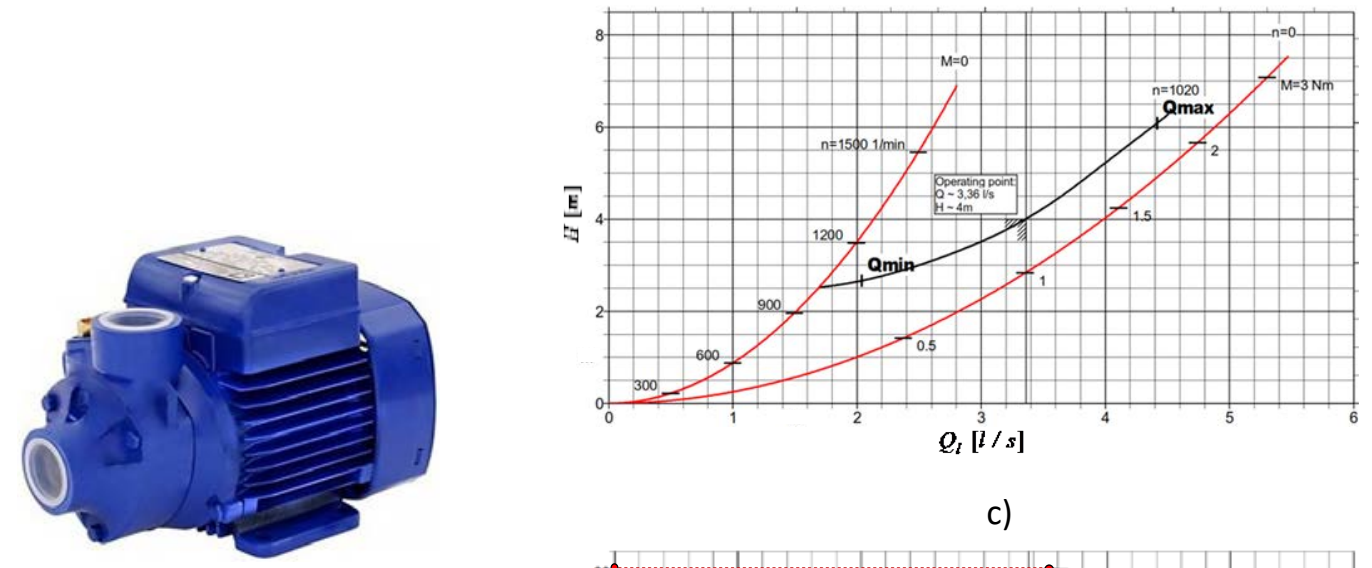

c)

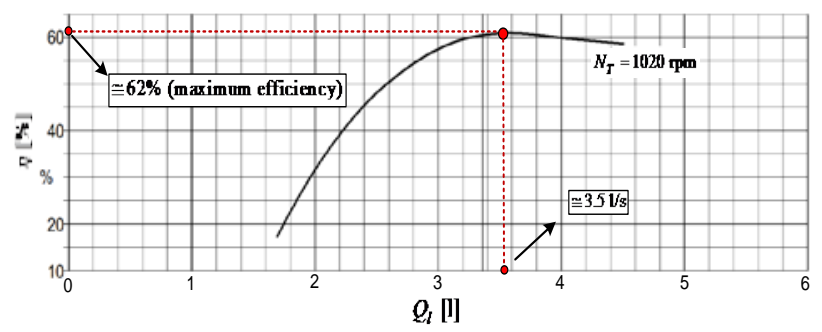

Fig. 2 - (a) Photo of the motor of the hydraulic turbine Etanorm 32- 125 KSB. (b) Flow versus head pressure turbine characteristic. (c) Turbine efficiency graph for its nominal speed of $1200 \mathrm{rpm}$.

In terms of power flow, and following Fig. 1, after the induction machine is magnetized by $Q_{S}$, that is supplied by the capacitors bank whose values depend on available power $\left(P_{H}\right)$ provided by the turbine, the generator supplies the active power $\left(P_{S}\right)$, that will be delivered to the load. However, the reactive power supplied by the capacitors needs to be sufficient for both machine excitation and electric load.

The main drawback of this SEIG-PAT system is its poor voltage and frequency regulation under variable electric loads and also variable turbine operating points. For example, a change in the electric load impedance directly influences the excitation level of the generator because reactive power supplied by capacitors is divided by both the generator and load. This effect also influences electric frequency of the generator (and consequently, its rotor speed) and thus stator voltage. The relationship between the capacitance of the capacitor bank, voltage, prime mover speed and frequency of the induced e.m.f in an isolated self-excited induction generator must be particularized. In it, both the stator voltage and frequency signals are unknown. They have to be calculated for a given speed, capacitance, and electric load impedance. To get better voltage regulation, the reactive current in the induction generator needs to be adjusted suitably during load variation, in other words, the excitation capacitances must change. However, when changing the magnetization level of the induction generator, one must be careful about possible magnetic saturation effects and thus its third harmonics impact in the self-excitation process. By another side, other operating conditions of the turbine can change due to several reasons. This will certainly affect the power delivered by the turbine, changing the generator electrical conditions presented to the load. 
In conclusion, the total efficiency of the SEIG-PAT system can be altered drastically during its life-time. Therefore, some cost-effective automatic tuning is needed, always searching for the highest possible efficiency system, which is addressed to follow.

\subsection{Automatic tuning methodology}

Hydraulic turbine and the induction generator are key in PAT devices, imposing together the overall system efficiency. Tuning some turbine parameters is a very costly and low reliable solution for low power. Of course, the same points can be passed to the induction generator itself. For example, an option for a rotor wound induction generator, instead of a squirrel-cage one, could be a possible tuning solution. However, the cost and the reliability are drawbacks. In this framework, the solution adopted and described in this section was to design a tuning methodology for capacitor bank values, which were automatically adjusted to maximize the system efficiency for each operating point of the PAT.

The minimum capacitance values needed to keep the generator excited for the no-load case can be easily determined by analysing the magnetizing curve of the induction machine, that can be experimentally obtained. However, for other operating points, capacitor bank needed to be adjusted, mainly to maximize the recovered energy.

The equivalent circuit of a SEIG with load and excitation capacitor is attached in Fig. 3, showing the active and reactive power flow. Here, the considered assumption was the machine only works in the linear zone (without saturation) and the iron losses can be neglibible. The equivalent circuit can be divided into three different parts, stator, magnetization and rotor. Parameters $R_{S}$ and $X_{S}$ represent the stator resistance and leakage reactance, respectively, and $X_{m}$ represents the magnetization reactance. Finally, for the rotor side, $X r$ and $R_{r / s}$ represent the reactance and resistance of the rotor, respectively. Considering a load type $R L$, the objective was to obtain an expression for the minimum capacitance required for the SEIG operation, depending on the rotor angular speed, on parameters of the machine, on the frequency of the generator and on the $R_{L}$ load.

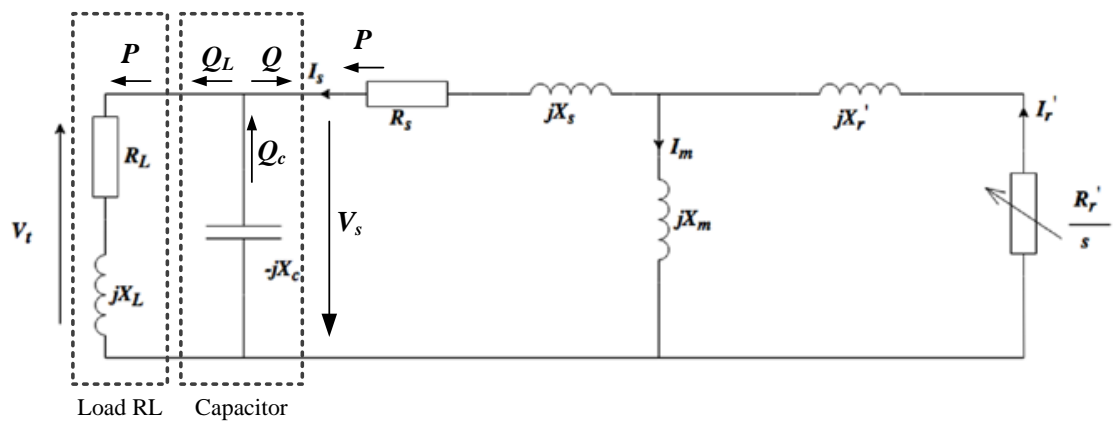

Fig. 3 - Equivalent circuit of a Self-Excited induction generator with the load and excitation capacitor (Eltamaly, 2002).

From Eltamaly (2002), one can compute the minimum required value of the capacitor bank for the SEIG, as in (1). Parameters $A_{1}$ to $A_{4}$ and $B_{0}$ to $B_{2}$ can be obtained using (3) and (4), where $b$ is the per unit rotor speed and $a$ is the ratio between $f$ and $f_{r}$.

$$
\begin{aligned}
& C_{\min }=\frac{1}{2 \pi a 50 X_{C}} \\
& X_{C}=-\frac{A_{4} a^{4}+A_{3} a^{3}+A_{2} a^{2}+A_{1} a}{B_{2} a^{2}+B_{1} a+B_{0}}
\end{aligned}
$$




$$
\begin{aligned}
& A_{4}=-X_{L} L_{3} ; A_{3}=X_{L} b L_{3} ; \\
& A_{2}=R_{L} R_{r} L_{2}+R_{L} R_{s} L_{1}+R_{s} R_{r} X_{L} ; A_{1}=-R_{L} R_{s} b L_{1} ; \\
& B_{2}=X_{L} L_{1}+L_{3} ; B_{1}=-b\left(X_{L} L_{1}+L_{3}\right) ; B_{0}=-R_{r}\left(R_{L}+R_{s}\right) \\
& L_{1}=X^{\prime}{ }_{r}+X_{m} \\
& L_{2}=X_{s}+X_{m} \\
& L_{3}=X_{s}\left(X^{\prime}{ }_{r}+X_{m}\right)+X_{r} X_{m}
\end{aligned}
$$

The per unit rotor speed $a$ can be calculated by solving (5), where parameters $C_{0}$ to $C_{4}$ are given by (6).

$$
\begin{aligned}
& C_{4} a^{4}+C_{3} a^{3}+C_{2} a^{2}+C_{1} a^{1}+C_{0}=0 \\
& C_{4}=R_{L} L_{3}{ }^{2}+R_{r} X_{L}{ }^{2} X_{m}{ }^{2}+R_{s} X_{L}{ }^{2} L_{1}{ }^{2} \\
& C_{3}=-b\left[2 R_{L} L_{3}{ }^{2}+R_{r} X_{L}{ }^{2} X_{m}{ }^{2}+2 R_{s} X_{L}{ }^{2} L_{1}{ }^{2}\right] \\
& C_{2}=R_{L}{ }^{2} R_{r} X_{m}{ }^{2}+R_{L}{ }^{2} R_{s} L_{1}{ }^{2}+R_{L} R_{r}{ }^{2} L_{2}{ }^{2}+2 R_{L} R_{r} R_{s} X_{m}{ }^{2}+R_{L} R_{s}{ }^{2} L_{2}{ }^{2}+ \\
& +R_{L} b^{2} L_{3}{ }^{2}+R_{s} X_{L}{ }^{2} R_{r}{ }^{2}+R_{s} X_{L}{ }^{2} b^{2} L_{1}{ }^{2} \\
& C_{1}=-b\left[R_{L}{ }^{2} R_{r} X_{m}{ }^{2}+2 R_{L}{ }^{2} R_{s} L_{1}{ }^{2}+2 R_{r} R_{L} R_{s} X_{m}{ }^{2}+2 R_{L} R_{s}{ }^{2} L_{1}{ }^{2}\right] \\
& C_{0}=R_{L}{ }^{2} R_{r}{ }^{2} R_{s}+R_{L}{ }^{2} R_{s} b^{2} L_{1}{ }^{2}+R_{L} R_{r}{ }^{2} R_{s}{ }^{2}+R_{L} R_{s}{ }^{2} b^{2} L_{1}{ }^{2}
\end{aligned}
$$

\subsubsection{Computational model - dynamic analysis}

The analytical model developed above provides the tools to compute and analyse the range of capacitances which are required for the self-excitation of a specific induction machine. With those, one can now perform a computational model to analyse the machine performance, using a numerical model. In the model simulation, the excitation capacitor and the $R_{L}$ load are connected to the machine and the prime mover is started and the transient and steady-state of the machine were analysed. The developed model enabled to perform two different analysis: the required range of the capacitor banks and the knowledge of the efficiency curves of the generator.

\subsection{Experimental application of the SEIG}

To validate the analytical and simulation results of the SEIG in the PAT system, two experimental set-ups were done: firstly, using a $D C$ motor as the prime mover, the SEIG electrical efficiency was measured and secondly, incorporating the SEIG in a hydraulic system to measure the overall behaviour and efficiency.

\subsubsection{SEIG electrical efficiency and minimum capacitance values}

The first experimental set-up was done using a $D C$ motor as the prime mover of the $S E I G$, to measure the efficiency of the SEIG under different loads and different excitation capacitances. With this experiment, it was possible to compute the minimum capacitance as a function of the load. For range of used resistances, between $120 \Omega \leq$ $R_{L} \leq 600 \Omega$, the resultant range of capacitances was $5 \mu F \leq C \leq 175 \mu \mathrm{F}$. The configuration of the set-up is shown in Fig. 4.

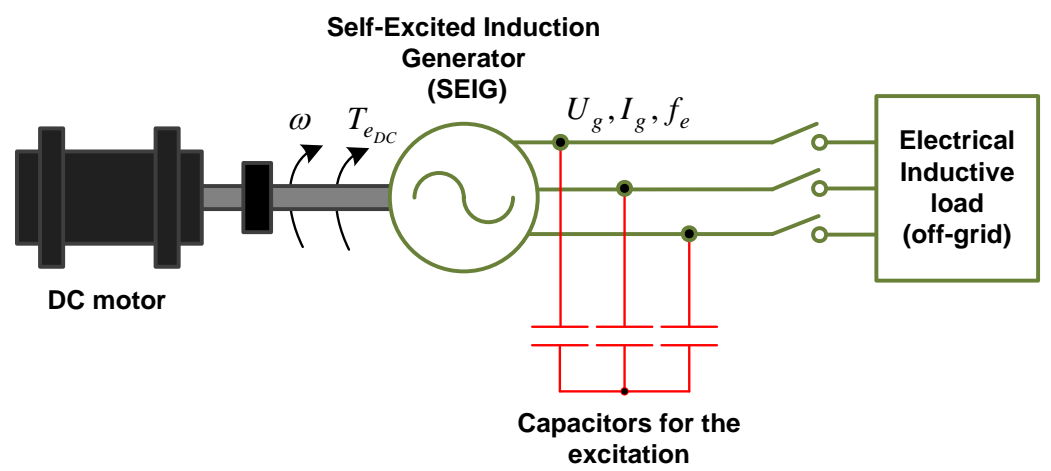


Fig. 4 - Scheme of experimental installation used for the tests

The estimation of the electrical efficiency $\left(\eta_{e l}\right)$ is described by equations (7), where $P_{s}$ is the generator output active power and $P_{\text {mec }}$ is the input mechanical power. The mechanical power can be computed given the input electrical power of the DC motor, $P_{D C}$, multiplied by its efficiency $\eta_{D C}$.

$$
\eta_{e l}=\frac{P_{S}}{P_{m e c}}, P_{S}=3 V_{S} I_{S} \cos \varphi, P_{m e c}=P_{D C} \eta_{D C}
$$

\subsubsection{Global efficiencies of the system and required capacitance values}

In the second experimental set-up, a pilot installation of the overall system (electrical + hydraulic) was assembled in CERIS-Hydraulic Lab of Instituto Superior Técnico from the Universidade de Lisboa, for a radial PAT machine. The rotational specific speed of the recovery system is $51 \mathrm{rpm}(\mathrm{m}, \mathrm{kW})$. This facility enabled to analyse its behaviour, when the SEIG was used in a PAT system. Fig. 5 shows the general hydraulic scheme and Fig. 6 illustrates the developed pilot installation. The tests were adapted according to the installed PAT in the hydraulic lab. The PAT was selected as a function of the available flow by the recirculating pump (Fig. 5) to guarantee a correct operation of the facility. The air vessel tank is sized for this facility and other independent connections that can be done in the hydraulic facility. The maximum pressure is 10 bar and the volume of $1 \mathrm{~m}^{3}$ enables to stabilise the steady flow and avoid the peak pressure in the phases of the unsteady flow. The pipe lengths (upstream and downstream of the PAT) are 100 meters in order to do experimental tests to study the unsteady flow. This facility was successfully used in other experimental research (Ramos et al., 2009).

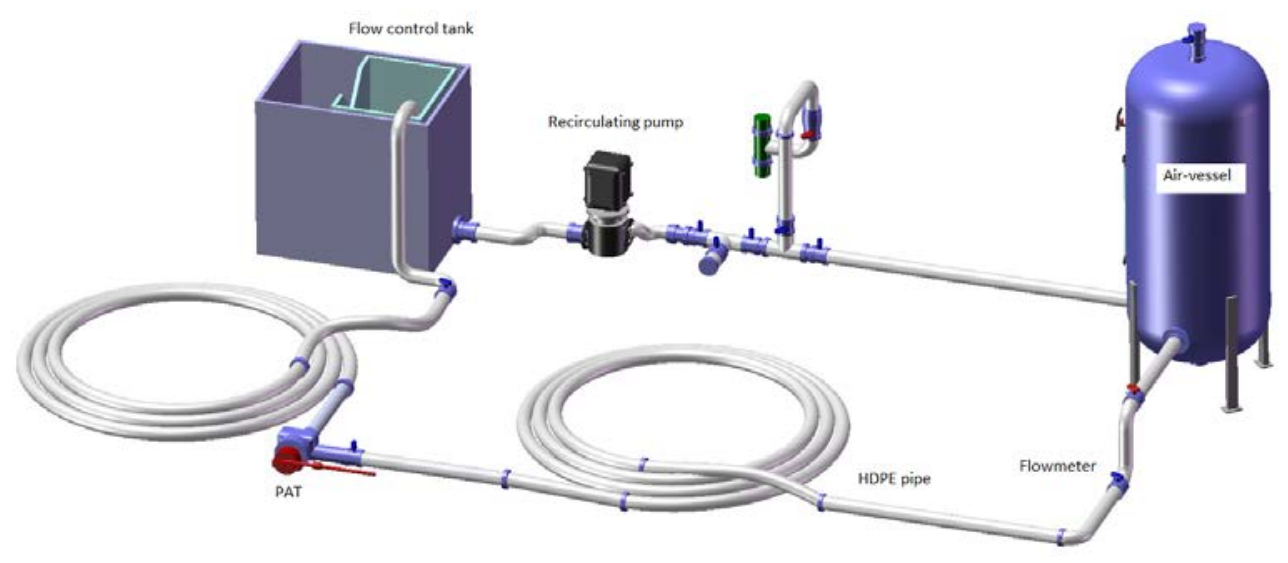

Fig. 5 - Scheme of the hydraulic system assembled (adapted from Ramos et al, 2009).

The elements, shown in Fig. 6, are the hydraulic machine (1); the electrical motor (2); the air vessel tank (3); the pressure sensor control (4); the multimeter to register current, voltage and power in each phase (5); the electrical load (6); the capacitance bank (7); the switch to connect and disconnect the capacitors (8); and the multimeter to measure the current (9). In the experimental tests, the discharge was measured by an electromagnetic flowmeter; the pressure was registered by pressure transducers through the picoscope data acquisition system; and the rotational speed was measured by a frequency meter. 

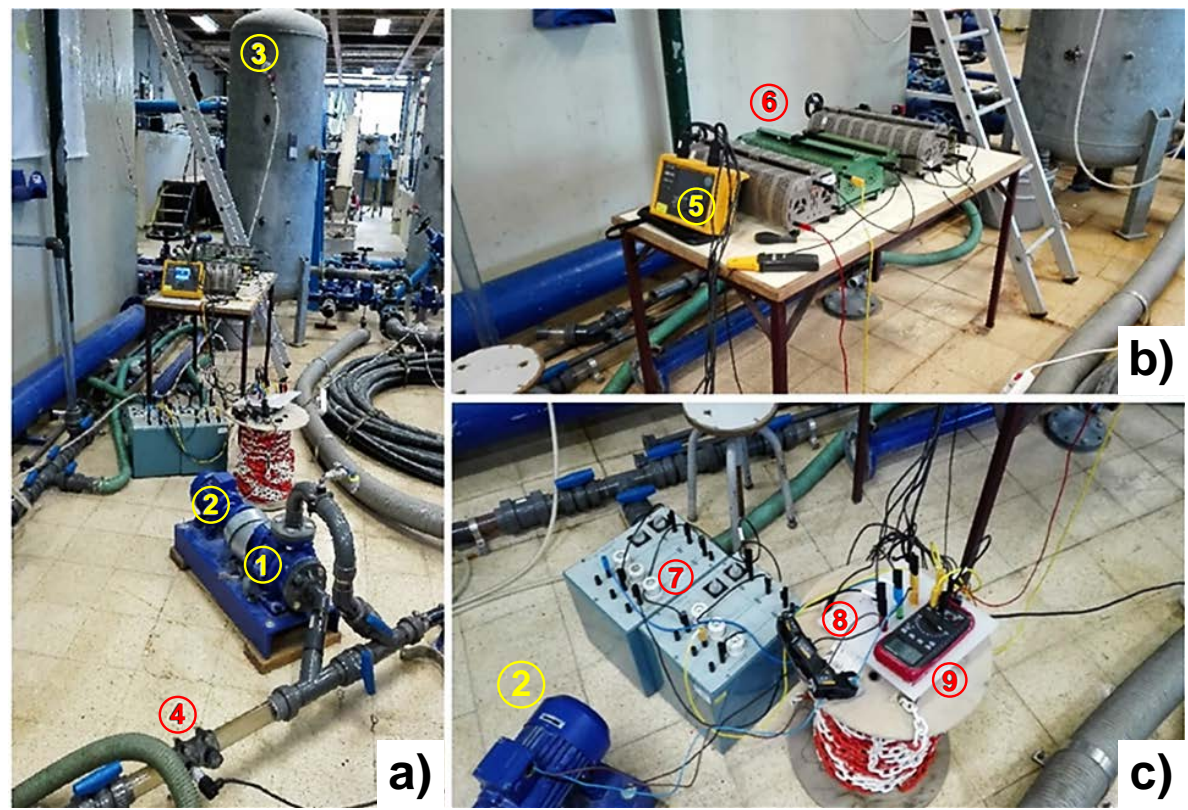

Fig. 6 - Photos of the experimental developed facility. (a) PAT general view, (b) Resistive load and (c) Switch and capacitors.

The experimental procedures were divided into two different types. Firstly, the analysis of the required capacitances to keep the generator excited by changing the load and the rotational speed. Secondly, when the results of the first set were known, specific operation points were chosen (i.e., load, capacitance and rotational speed), establishing a rotational speed and testing the SEIG-PAT system for different hydraulic conditions, in order to estimate the system global efficiency curves.

The range of used capacitances was the same as for the previous experimental work, between $5 \mu \mathrm{F} \leq C \leq 175 \mu \mathrm{F}$, for resistive loads between $120 \Omega \leq R_{L} \leq 600 \Omega$. The global efficiency of the system $\left(\eta_{\text {global }}\right)$ was estimated using the measured values, in which, $P_{S}$ represents the active power of the generator, and $P_{h y d}$ represents the available hydraulic power in W, (8). Using (7) and (8) it is possible to compute the PAT efficiency ( $\left.\eta_{\text {PAT }}\right)$.

$$
\eta_{\text {global }}=\frac{P_{S}}{P_{\text {hyd }}}=\eta_{e l} \eta_{P A T}, P_{S}=3 V_{S} I_{S} \cos \varphi, P_{\text {hyd }}=\rho g Q_{i} H_{i}
$$

where $\rho$ is the density of the fluid in $\mathrm{kg} / \mathrm{m}^{3}$, g is the gravity constant in $\mathrm{m}^{2} / \mathrm{s}, Q_{i}$ is the circulating flow in $\mathrm{m}^{3} / \mathrm{s}$, and $H$ is the recovered head in $\mathrm{m}$ w.c.

\section{$3 \quad$ Results and Discussion}

\subsection{Analytical and Simulation Model Results}

A comparison between the analytical and simulation models was done. Using the analytical model in (1) and the simulation model of the machine, the capacitance range was estimated as a function of the rotational speed and of the load.

The range of resistive loads was between $0 \Omega$ and $600 \Omega$. Remember that, the lower the electrical resistance is, the higher is the demanded load. Fig. 7 shows the results of the capacitance variation for both anaytical and simulation models. Analysing this figure, for a specific load, the applied capacitance value influenced highly the rotor speed. The capacitance required to keep the generator excited increases as the rotor speed decreases. The same occurres for the load variation, where higher loads (lower resistances) require higher capacitance values, for the same speed.

According to the results, the range of required capacitances to assure the rotor speed interval was between 5 and $225 \mu \mathrm{F}$ for the analytical model, while the values for the first simulation were between 7.5 and $180 \mu \mathrm{F}$. The required capacitance highly influenced the generator speed, and it depended on the load applied. For lower loads, the required capacitance presented small variations, however, as the load increases, the required capacitance 
increased more and more. Another important aspect was the decrease of the rotor speed when the load is higher, as shown in $R_{L}=120 \Omega$.

The trend of both simulation and model results is similar, but the variances overestimate and underestimate at lower and higher rotor speeds, respectively. These deviations can be explained by the negligence of the Rm parameter in model (1), that comprises the effect of the electrical machine iron losses. Typically, for higher rotor speeds, iron losses increase, which will have the same effect as increasing the load of the machine and, therefore, requiring higher values of capacitances (simulation results are higher than the model (1) ones). For lower rotor speeds, iron losses decrease and thus the opposite effect is visible.

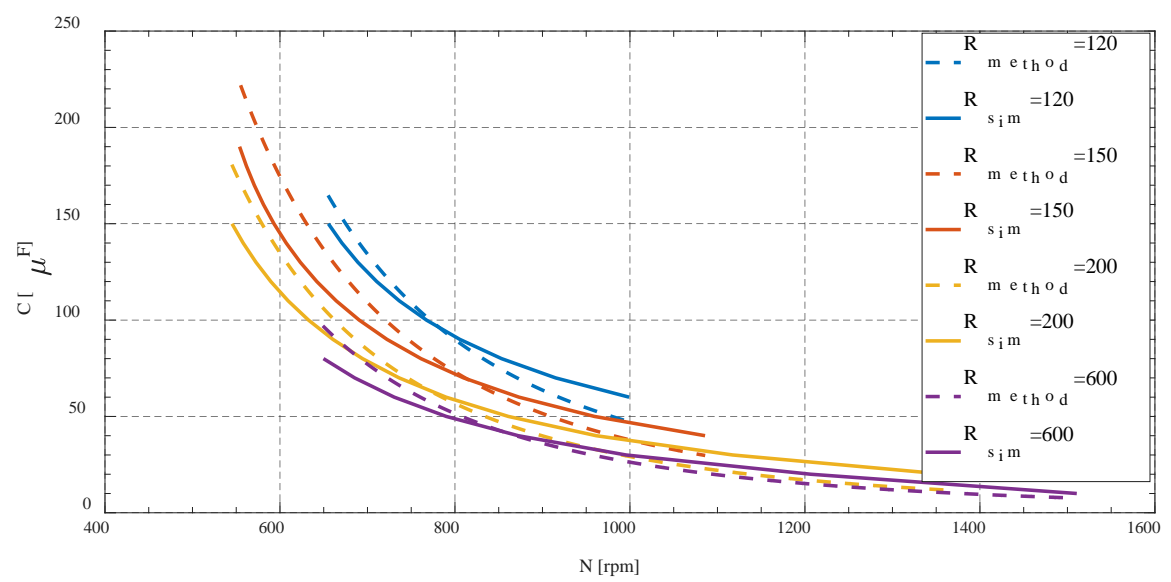

Fig. 7 - Capacitance required as function of rotational speed of generator, for specific resistive loads. In continuous lines, the values obtained using the simulation diagram and in dashed lines the ones obtained using the method (1).

In the first simulation stage, the two developed models presented some differences of results, but the general behaviour of the SEIG was similar, and so, the performed simulation showed the SEIG presented considerable limitations as consequence as the bank capacitance and the load values had a high influence.

\subsection{Experimental application of the SEIG}

\subsubsection{Analysis of required capacitances and generator performances ( $1^{\text {st }}$ Experiment)}

Fig. 8 shows the determined values for the experimental and the simulation capacitances when different rotor speed were considered. The experimental results, for the capacitances behaviour, were similar to simulation results, showing the increase on the capacitance values when the rotor speed decreases.

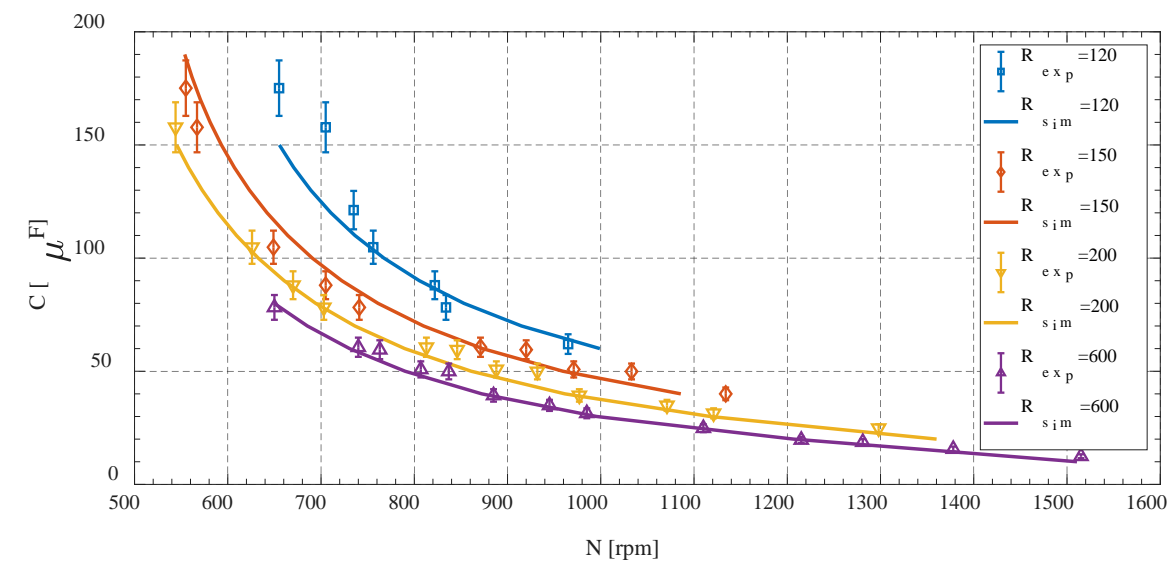

Fig. 8 - Experimental and simulation results as a function of rotational speed of generator, for constant values of load.

The experimental efficiency curves of the generator were determined, using (8). Fig. 9 shows similar results of electrical efficiencies for different loads $\left(120 \Omega \leq R_{L} \leq 600 \Omega\right)$. The maximum electrical efficiency was got using a load of $265 \Omega$. The maximum electrical efficiency decreased for higher (120 $\Omega$ ) and lower (600 $\Omega$ ) loads. 
Analysing the electrical efficiency curves of the generator for each load, there was a point of maximum efficiency. The point of maximum efficiency for all loads was with the minimum capacitance needed (highest rotor speeds) to keep the generator excited in this case. This emphasised the importance of calculating the minimum capacitance required for the SEIG operation.

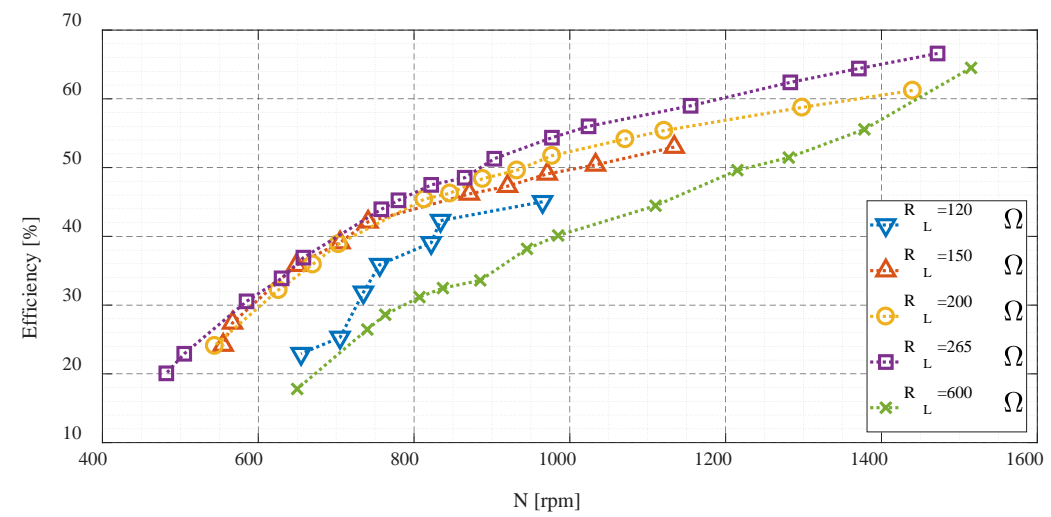

Fig. 9 - Graphic of the SEIG efficiency variation as a function of rotational speed, for constant load values.

Fig. 10 presents the minimum required capacitance for the SEIG as a function of the load. When the load was lower $230 \Omega$, the capacitance value started to increase exponentially, and when the load was higher than $230 \Omega$, the capacitance value decreased. This behaviour caused a limitation of electrical efficiency for those cases, because its maximum points were achieved for speeds between 1200 and $1500 \mathrm{rpm}$, Fig. 9, where $\eta_{e l} \geq 60 \%$, and so, if the maximum speed decreases, at some point, it will not be able to reach the best efficiency zone.

Therefore, the SEIG application presented some limitations that need to be carefully analysed, because depending on the load and rotor speed intended, this induction machine may or may not be a good fit for that specific application.

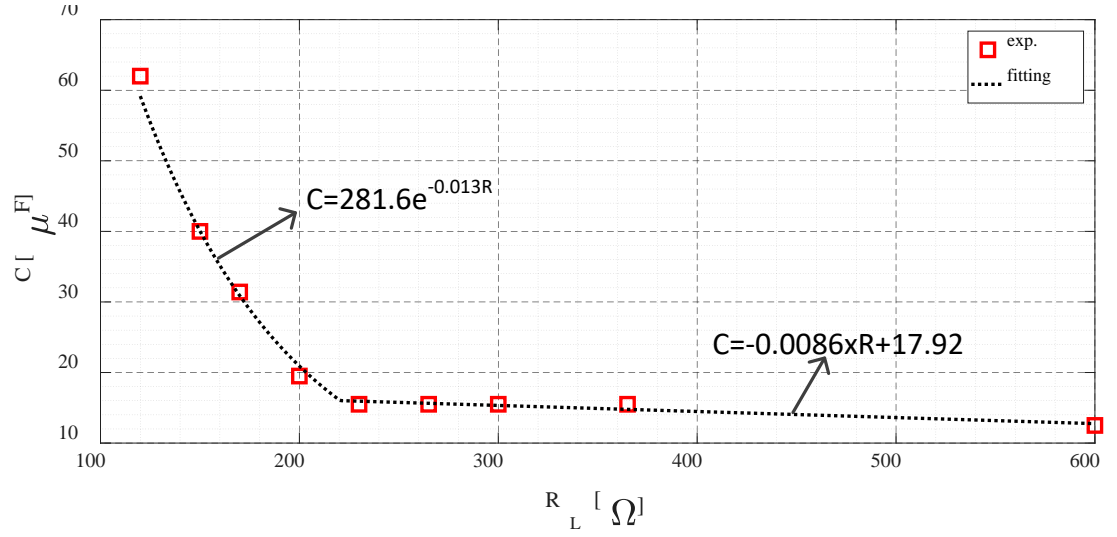

Fig. 10 - Graphic of minimum capacitance as a function of load

\subsection{SEIG Experimental Application to a Hydraulic System $\left(2{ }^{\text {nd }}\right.$ Experiment $)$}

Fig. 11 shows the results for the capacitance range with rotor speed are shown for each applied load, considering the SEIG applied in the experimental set-up of the closed loop hydraulic system. In this case, different from the previous ones, where the SEIG was powered by a DC machine, the lowest possible resistive load to keep the machine self-excited was $R_{L}=113 \Omega$. As the load increased, the range of the operation rotor speeds decreased. As example, for loads of $120 \Omega$ and $113 \Omega$, the maximum speeds were around $850 \mathrm{rpm}$. 


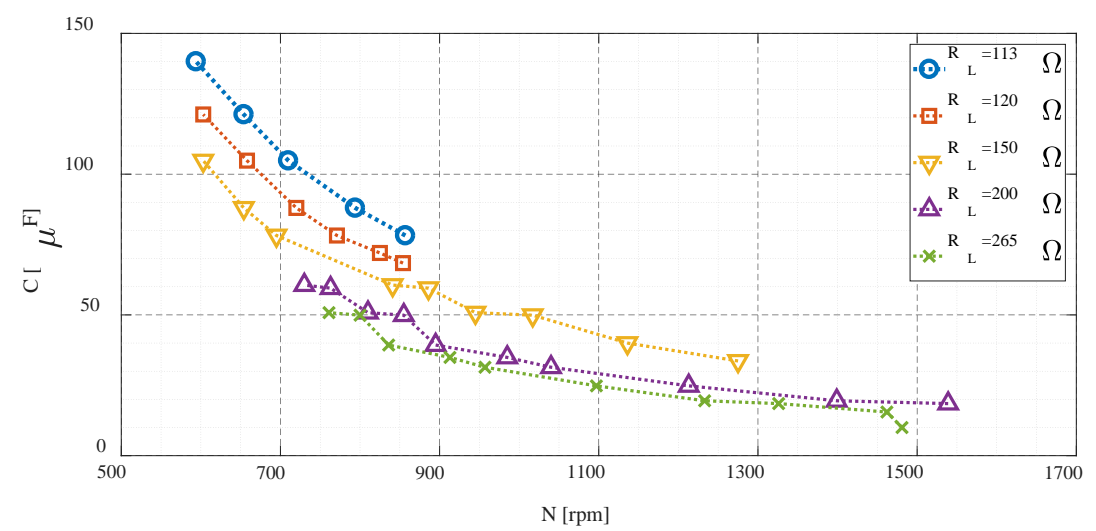

Fig. 11 - Capacitance required as function of the rotor speed, in a steady flow condition.

The global efficiency values depended highly on the flow and head values that determined the turbine efficiency. Therefore, the experiment was executed for different values of loads and capacitances to establish different values of rotor speeds. Table 2 lists the different pairs of resistive loads and capacitances which were chosen for these experimental tests as well as the respective maximum electrical efficiencies. The electrical efficiency was got using the results of Fig. 9, in which the SEIG was tested with the DC motor.

Table 2 - Load and capacitance combinations used to stablish the speed values for the tests below.

\begin{tabular}{cccc}
\hline \hline $\mathrm{N}(\mathrm{rpm})$ & $\mathrm{R}_{\mathrm{L}}(\Omega)$ & $\mathrm{C}(\mu \mathrm{F})$ & $\eta_{\text {el }}(\%)$ \\
\hline 1525 & 230 & 15.5 & 61.0 \\
\hline 1370 & 230 & 18.5 & 61.8 \\
\hline 1200 & 265 & 19.5 & 59.8 \\
\hline 1130 & 230 & 24.8 & 58.2 \\
\hline 1050 & 230 & 31.4 & 55.7 \\
\hline 930 & 230 & 34.9 & 50.8 \\
\hline 810 & 230 & 49.9 & 44.6 \\
\hline \hline
\end{tabular}

Fig. 12 shows the global efficiency as a function of the flow for the values of Table 2.

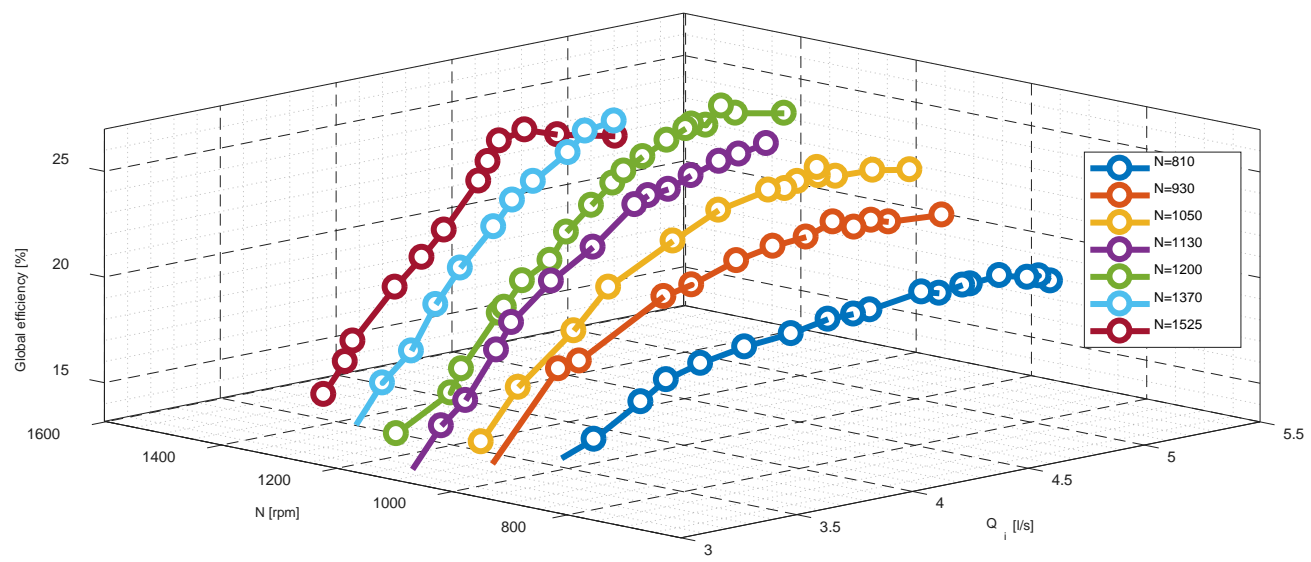

Fig. 12 - Global efficiency as function of flow, for different rotational speeds.

Table 3 shows the maximum global, the electrical and the PAT efficiencies points for each speed. The best global efficiency points of each curve were registered for flow values between 4,0 l/s and 5,0 l/s. The highest efficiencies were achieved for the curve $N=1200 \mathrm{rpm}$, and the efficiency values were around $27 \%$. In addition, for flows 
lower than $3.5 \mathrm{l} / \mathrm{s}$, the system efficiency was never higher than $20 \%$. For flows below $2.5 \mathrm{l} / \mathrm{s}$, the system stopped to generate energy. Therefore, when applying this system to a water distribution network, in which there are high variations of flow and pressure, this effect must be taken into account. The difference between electrical efficiency of the rotor and the global efficiency when the PAT was operated is related with the hydraulic losses of the recovery systems as well as the reactive power consumed by the capacitors. When Fig. 12 is observed, there is a difference between efficiency connected on the grid (62\%) and off-grid (27\%). This difference is due to reactive power introduced by the SEIG. This low efficiency value can cause the unfeasibility of these recovery projects. However, this efficiency can be improved whether the generator is changed and it is different to defined by the manufacturer. The definition of electrical parameters of the generator $\left(X_{m}\right.$ and $\left.R_{r / s}\right)$ are future research lines in which the studies should deep in order to increase the efficiency and therefore, the feasibility of these installations. A correct definition of magnetization reactance and resistance of the generator are key in the increase of the efficiency since the internal losses change according to these values as well as the capacitance value to excite the rotor.

Table 3 - Maximum global, electrical and PAT efficiencies points for each speed.

\begin{tabular}{ccccc}
\hline \hline $\mathrm{N}(\mathrm{rpm})$ & $\mathrm{Q}_{\mathrm{i}}(\mathrm{l} / \mathrm{s})$ & $\eta_{\text {global }}(\%)$ & $\eta_{\text {el }}(\%)$ & $\eta_{\text {PAT }}(\%)$ \\
\hline \hline 810 & 4.9 & 20.3 & 61.0 & 45.6 \\
\hline 930 & 4.5 & 23.1 & 61.8 & 45.5 \\
\hline 1050 & 4.7 & 24.5 & 59.8 & 44.0 \\
\hline 1130 & 4.7 & 25.3 & 58.2 & 43.4 \\
\hline 1200 & 4.7 & 26.7 & 55.7 & 44.5 \\
\hline 1370 & 4.6 & 25.1 & 50.8 & 40.6 \\
\hline 1525 & 4.6 & 23.8 & 44.6 & 39.1 \\
\hline \hline
\end{tabular}

Fig. 13 are shown the PAT efficiencies computed using (8) and the results of the electrical and global efficiencies. The PAT efficiency showed its maximum values for flows between 4,0 l/s and 5,0 l/s. However, its maximum points were for rotor speeds of 810 and $930 \mathrm{rpm}$. Therefore, the maximum efficiency areas of the PAT and generator are not the same, and so, the system was not optimized.

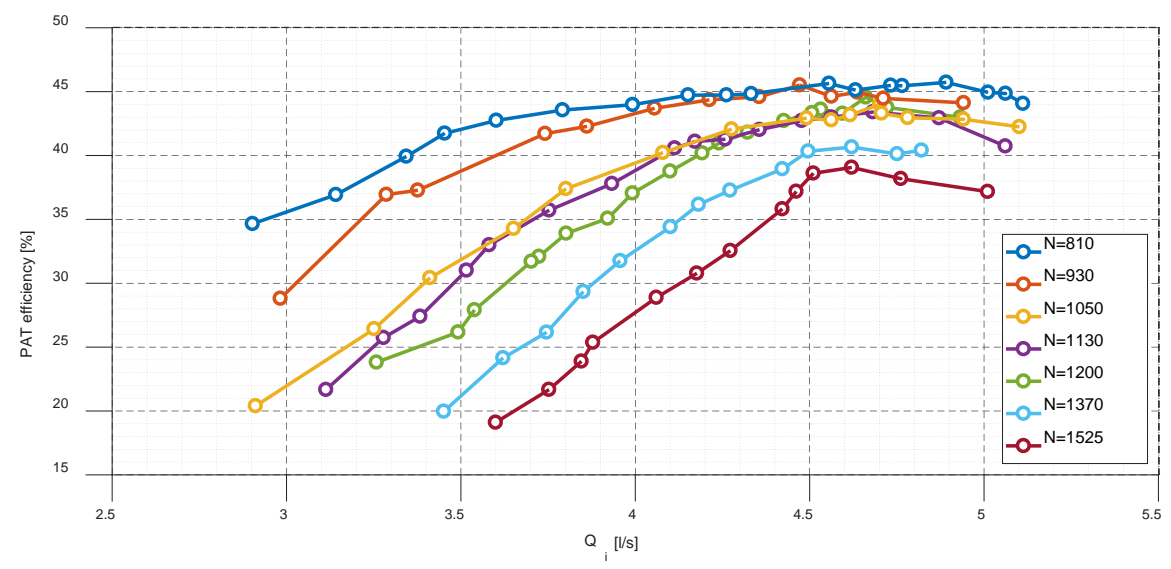

Fig. 13 -PAT efficiency curves as a function of flow for different rotational speeds.

Finally, from the same data of the results of Fig. 12, the hydraulic curves $(Q-H)$ are shown for each speed and for the runaway working condition. An important observation of the obtained results of Fig. 14 was the existence of an inferior limit of flow in which for lower values, the generator stop being excited and generating energy. This value depends on the rotor speed, which is a reflexion of the capacitance value applied to the generator. As shown in this figure, when the rotor speeds was high, the range of flow was lower in the operating region. 


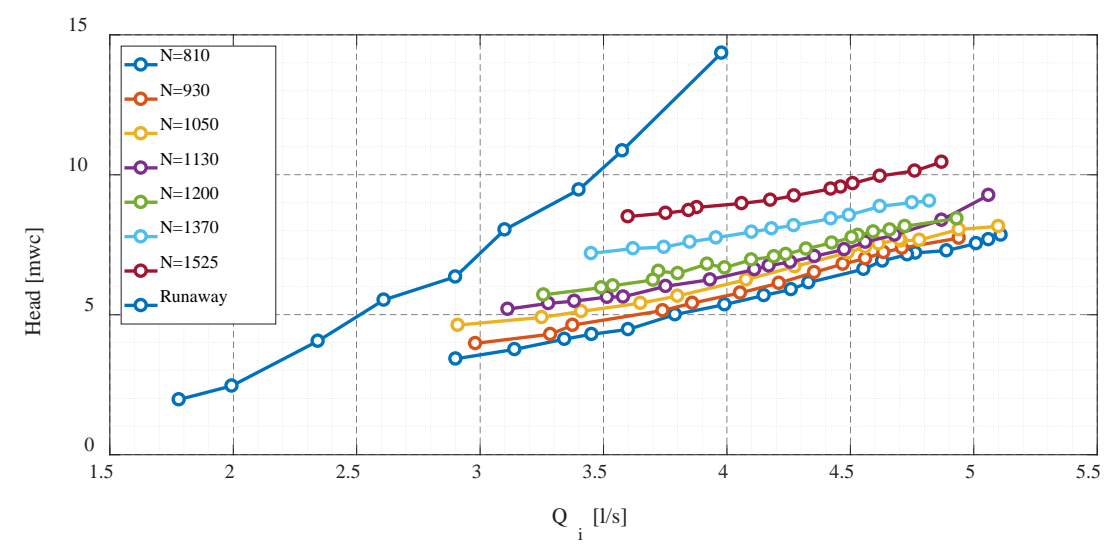

Fig. 14 - Hydraulic curves $(Q-H)$ of the PAT in steady flow conditions.

\section{CONCLUSIONS}

This paper studied the use of a low power PAT-SEIG off-grid system in a real experimental facility to be applied in remote areas where the access to the electrical grid is difficult or non-existent. The use of recovery systems provides the advantage of the pressure reduction and consequently water loss control in water distribution networks, as well as the simultaneous energy recovery. The possible applications of these configurations are high, as water distribution systems in urban and hydraulic systems are avid of feasible solutions for improving waterenergy performance indicators.

Results showed that this solution can be a feasible alternative, if the capacitor bank for SEIG self-excitation is tuned to maximize the PAT-SEIG electric energy efficiency. Consequently, an automatic tuning system was proposed and experimentally tested in laboratory. This operation scheme predicted reliable capacitance values depending on PAT-SEIG, that changed according to hydraulic constrains fluctuations as well as its load impedance. These variations will always occur when different pressure drop values are demanded. The development of this ensemble PAT-SEIG enables the energy recovery in water distribution networks, in which the hydraulic machines operate off-grid (e.g., remote areas, rural areas, farmers, irrigation zones).

Comparison between experimental data and analytic modeling approach pointed out the PAT-SEIG energy efficiency has a high nonlinear dependence on flow rate, on capacitor bank values and, of course, on the electric load impedance, with differences generally lower than 20-25\%. The proposed methodology can be an effective technique for the selection and application of low power PAT-SEIG systems for pressure control in water distribution networks due to its universality and practicality type.

The proposed automatic tuning has been tested assuming that parameters of the equivalent electric circuit of the induction machine are constant for all operating points. If some of them show major changes, a new set of "optimal" set of capacitances should be selected. Further experiments are required, in order to test different models of single, vertical multistage pumps, parallel and series PATs for assessing whether different relationships are required or if differences fall within the uncertainties of experimental expected tests.

New configurations and experiments are in progress, in order to verify, not only, which generator parameters have significant variations during these new PAT-SEIG operations, but also for studying and analyzing a new approach for the induction generator system to compensate any fluctuation in its output caused by possible flow instabilities.

Acknowledgments: This research is supported by Academic program career of the faculty of the Universitat Politècnica de València 2016/2017 in the project "Maximization of the global efficiency in PATs in laboratory facility" and by FCT, through IDMEC, under LAETA, project UID/EMS/50022/2013. Besides, the authors wish to thank to the project REDAWN (Reducing Energy Dependency in Atlantic Area Water Networks) EAPA_198/2016 from INTERREG ATLANTIC AREA PROGRAMME 2014-2020 and CERIS (CEHIDROIST), the Hydraulic Laboratory, for the support in the conceptual work and in experiments on PATs.

\section{Conflicts of Interest:}

The authors declare no conflict of interest. 
The founding sponsors had no role in the design of the study; in the collection, analyses, or interpretation of data; in the writing of the manuscript, and in the decision to publish the results.

\section{REFERENCES}

Ayodele, T. R., A. S. O. Ogunjuyigbe, and B. B. Adetokun. "Optimal capacitance selection for a wind-driven selfexcited reluctance generator under varying wind speed and load conditions." Applied Energy 190 (2017): 339353.

Balkhair, Khaled S., and Khalil Ur Rahman. "Sustainable and economical small-scale and low-head hydropower generation: A promising alternative potential solution for energy generation at local and regional scale." Applied Energy 188 (2017): 378-391.

Buono, D., Frosina E., Mazzone, A., Cesaro, U., Senatore, A. Study of a Pump as Turbine for a Hydraulic Urban Network Using a Tridimensional CFD Modeling Methodology, In Energy Procedia, Volume 82, 2015, Pages 201208, doi: 10.1016/j.egypro.2015.12.020.

Barbarelli, S., Amelio, M., Florio, G., 2017. Experimental activity at test rig validating correlations to select pumps running as turbines in microhydro plants. Energy Convers. Manag. doi:10.1016/j.enconman.2017.03.013

Carravetta, A., Del Giudice, G., Fecarotta, O., Ramos, H., 2013. PAT Design Strategy for Energy Recovery in Water Distribution Networks by Electrical Regulation. Energies 6, 411-424. doi:10.3390/en6010411

Carravetta, A., Del Giudice, G., Fecarotta, O., Ramos, H., 2012. Energy Production in Water Distribution Networks: A PAT Design Strategy. Water Resour. Manag. 26, 3947-3959. doi:10.1007/s11269-012-0114-1

Carravetta, A., Fecarotta, O., Del Giudice, G., Ramos, H., 2014. Energy Recovery in Water Systems by PATs: A Comparisons among the Different Installation Schemes. Procedia Eng. 70, $275-284$. doi:10.1016/j.proeng.2014.02.031

de Oliveira e Silva, G., Hendrick, P., 2016. Pumped hydro energy storage in buildings. Appl. Energy 179, 12421250. doi:10.1016/j.apenergy.2016.07.046

Eltamaly, A.M., 2002. New formula to determine the minimum capacitance required for self-excited induction generator, in: 33rd Power Electronics Specialists Conference. doi:10.1109/PSEC.2002.1023854

Fecarotta, O., Carravetta, A., Ramos, H.M., Martino, R., 2016. An improved affinity model to enhance variable operating strategy for pumps used as turbines. J. Hydraul. Res. 1686, 1-10. doi:10.1080/00221686.2016.1141804

Khaled S. Balkhair, Khalil Ur Rahman, Sustainable and economical small-scale and low-head hydropower generation: A promising alternative potential solution for energy generation at local and regional scale, In Applied Energy, Volume 188, 2017, Pages 378-391, doi: 10.1016/j.apenergy.2016.12.012.

Lima, G.M., Edevar L., and Bruno M. B.. "Selection and location of Pumps as Turbines substituting pressure reducing valves." Renewable Energy 109 (2017): 392-405.

Longo, S., d’Antoni, B.M., Bongards, M., Chaparro, A., Cronrath, A., Fatone, F., Lema, J.M., Mauricio-Iglesias, M., Soares, A., Hospido, A., 2016. Monitoring and diagnosis of energy consumption in wastewater treatment plants. A state of the art and proposals for improvement. Appl. Energy 179, 1251-1268. doi:10.1016/j.apenergy.2016.07.043

Menke, R., Abraham, E., Parpas, P., Stoianov, I. Demonstrating demand response from water distribution system through pump scheduling, In Applied Energy, Volume 170, 2016, Pages 377-387, doi: 10.1016/j.apenergy.2016.02.136.

Pearre, N.S., Swan, L.G., 2015. Technoeconomic feasibility of grid storage: Mapping electrical services and energy storage technologies. Appl. Energy 137, 501-510. doi:10.1016/j.apenergy.2014.04.050

Pérez-Sánchez, M., 2017. Methodology for energy efficiency analysis in pressurized irrigation networks. Practical application. Universitat Politècnica de València. 
Pérez-Sánchez, M., Sánchez-Romero, F., Ramos, H., López-Jiménez, P., 2017. Energy Recovery in Existing Water Networks: Towards Greater Sustainability. Water 9, 97. doi:10.3390/w9020097

Pérez-Sánchez, M., Sánchez-Romero, F., Ramos, H., López-Jiménez, P., 2016. Modeling Irrigation Networks for the Quantification of Potential Energy Recovering: A Case Study. Water 8, 1-26. doi:10.3390/w8060234

Power, C., Coughlan, P., McNabola, A., 2017. Micro-Hydropower Energy Recovery at Waste Water Treatment Plants: Turbine Selection and Optimisation, Journal of Energy Engineering, 143, (1), , p1-7

Ramos, H.M., Borga, A., Simão, M., 2009. New design solutions for low-power energy production in water pipe systems, Water Science and Engineering 2 (4), 69-84, doi:10.3882/j.issn.1674-2370.2009.04.007

Ramos, H., Borga, A., 1999. Pumps as turbines: an unconventional solution to energy production, Urban Water 1 (3), 261-263, doi:10.1016/S1462-0758(00)00016-9

Ramos, H., Borga, A., 2000. Pumps yielding power, Dam Engineering, Water Power \& Dam Construction 10 (4), 197-217

Ramos, J.S., Ramos, H.M., 2009. Solar powered pumps to supply water for rural or isolated zones: a case study. Energy for Sustainable Development 13 (3), 151-158, doi: 10.1016/j.esd.2009.06.006

Romero, L., Pérez-Sánchez, M., Amparo López-Jiménez, P., 2017. Improvement of sustainability indicators when traditional water management changes: a case study in Alicante (Spain). AIMS Environ. Sci. 4, 502-522. doi:10.3934/environsci.2017.3.502

Rossi, M., Righetti, M., Renzi, M. Pump-as-turbine for Energy Recovery Applications: The Case Study of An Aqueduct, In Energy Procedia, Volume 101, 2016, Pages 1207-1214, doi: 10.1016/j.egypro.2016.11.163.

Samora, I., Franca, M.J., Schleiss, A.J., Ramos, H.M., 2016. Simulated annealing in optimization of energy production in a water supply network, Water resources management 30 (4), 1533-1547, doi: 10.1007/s11269-0161238-5 